\title{
The effect of relative humidity on incompatibility and fertility in Brassica oleracea L.
}

\author{
N. P. A. van Marrewijk* and D. L. Visser \\ Institute for Horticultural Plant Breeding (IVT), Wageningen, the Netherlands
}

Key words: Brassica oleracea, incompatibility, pseudocompatibility, relative humidity, pollen fertility

\section{Summary}

Research on the effect of relative humidity on incompatibility and fertility in Brassica oleracea $\mathrm{L}$. was carried out under fully controlled environmental conditions. Clones of Brussels Sprouts and cabbage with different $S$-genotypes were placed at 55,80 and $95 \%$ relative humidity. Incompatible selfings and compatible crosses were made using pollen ripened in the same and in the other environments. Fertility and incompatibility were assessed by counting the numbers of pollentubes that had penetrated into the styles. A humidity effect on incompatibility could not be demonstrated, but pollen ripened at $95 \%$ relative humidity showed lower fertility. This decreased fertility might be the result of premature pollen germination at very high relative humidity.

\section{Introduction}

The occurrence of inbred plants (sibs) in hybrid varieties of Brassica crops is mainly due to incomplete functioning of the incompatibility mechanism under certain environmental conditions. In literature research on the influence of temperature on self incompatibility, pseudocompatibility, fertility and seed production has been extensively described but up to now little attention has been paid to the influence of relative humidity $(\mathrm{RH})$ on self incompatibility and fertility in crucifers. Oelke (1957), Christ (1959), Kroh \& Linskens (1963, 1967) and Tatebe (1964) studied pollen germination and pollen tube growth after self pollination under high humidity conditions mainly before penetration into the styles. They found an increase in pollen germination and tube growth at very high humidity. Oelke (1957) and Tatebe (1964) also reported very small numbers of pollen tubes that had penetrated into the styles, resulting in fertilization in radish under these high humidity conditions. Lawson (1974) did some research on the effect of RH on speudocompatibility in Brussels sprouts, but could not draw definite conclusions. Carter \& McNeilly (1975)

* Present address: Government Institute for Research on Varieties of Cultivated Plants (RIVRO), c/o IVT, P.O. Box 16, Wageningen, the Netherlands. 
investigated the influence of increased humidity during the first hours after self pollination and found an increase of pollen tube penetration. To obtain more information we started an investigation on the influence of RH on incompatibility in 1973. Our early results were already published (van Marrewijk \& Visser, 1974). The investigation was continued on a much larger scale in 1976. The results are published in this paper.

\section{Materials and methods}

Self-incompatible clones of Brussels sprouts and a rather self-compatible clone of cabbage, homozygous for their incompatibility alleles ( $S$ genes), were used. The Brussels sprouts clones originated from various sources and differed strongly for their genetic backgrounds. The $S$ genes of most clones used belong to the weak $\left.S_{5}, S_{2}\right)$ or the medium strong $\left(S_{7}, S_{45}\right)$ groups (van Hal, personal communication). Details of the material are given in Table 1.

The effect of $\mathrm{RH}$ was investigated in three growth rooms of the IVT phytotron (Smeets, 1978) under fully controlled conditions at a day temperature of $21^{\circ} \mathrm{C}$ and a night temperature of $16^{\circ} \mathrm{C}$. The RH was 55,80 and $95 \%$, deviations being less than $5 \%$. The adjustment of $\mathrm{RH}$ to the changing temperature conditions occurred within half an hour. In addition, plants of the same clones were placed in a temperature controlled glasshouse kept at $17{ }^{\circ} \mathrm{C}$ and a $\mathrm{RH}$ of about $75 \%$ (variation from 65 to $80 \%$ ) to ensure the supply of vital pollen.

The photoperiod in the climate rooms was 12 hours and the light intensity at plant height about $48 \mathrm{~W} / \mathrm{m}^{2}$. From data provided by the Department of Physics and Meteorology of the Agricultural University at Wageningen it could be calculated that the mean light intensity in the glasshouse was about $85 \mathrm{~W} / \mathrm{m}^{2}$ during the flowering period.

In each environment about 10 days before flowering two to three plants of each clone were placed. Flowering occurred in March 1976. The following pollinations were made.

1. Self pollinations (geitonogamous) with pollen of the same clone ripened in the same and in the other environments. Because of labour shortage self-pollinations with pollen and styles from the $80 \% \mathrm{RH}$ room could not be realized. The pollinations were carried out throughout the flowering period, using young (day after anthesis) and old flowers (prior to wilting). For each combination of pollen and style environment and flower stage about 8-15 flowers were selfed per clone each time.

2. Cross pollinations with compatible pollen of certain clones ripened in the same and in the other environments. The cross pollinations were made on styles of open flowers one to three days old, and carried out 3 or more times during the experiment. For each cross about five flowers were pollinated each time. These cross pollinations were made to study the effect of $\mathrm{RH}$ on compatible combinations and to test pollen and style viability and fertility.

The pollinations were carried out at two- or three-day intervals with pollen from 
flowers one to three days old. In the $95 \% \mathrm{RH}$ room pollen of somewhat older flowers had to be used, because of the delayed dehiscence of the anthers under these conditions. In Table 2 the numbers of styles assessed are presented (in brackets) for selfings and cross pollinations in all combinations.

Self-pollinated styles were harvested about 48 hours, cross-pollinated styles 24 hours after pollination. Pollen tube penetration was assessed by the UV fluorescence method, described by Kho \& Baër (1968).

\section{Results and discussion}

From the many data the mean numbers of pollen tube penetrations per style were calculated for the various self- and cross-combinations (see Table 2).

The main effects have been calculated as mean values over all pollen environments or all style environments for each clone and are presented in Fig. 1 to 4.

\section{Style environment}

In Fig. 1 the mean pollen tube penetrations after incompatible self-pollination in the old flower stage are presented. For most clones the mean number of pollen tube penetrations at $95 \%$ was nearly as high as at $55 \% \mathrm{RH}$. Only clones 103.4 (selfcompatible) and $100.2\left(S_{7} S_{7}\right)$ showed an obvious decrease in pollen tube penetration with increasing $\mathrm{RH}$; clone 97.2 , on the contrary, a slight increase, but the results for the last clone are based on a small number of pollinations. When young

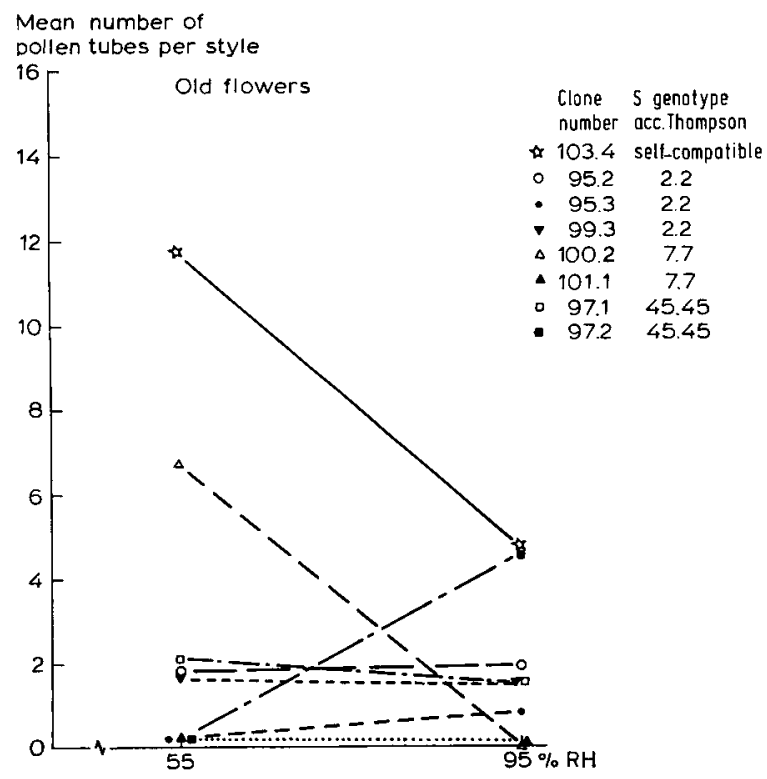

Fig. 1. Mean pollen tube penetration into the styles after selfing of old flowers (mean values over all pollen environments). 

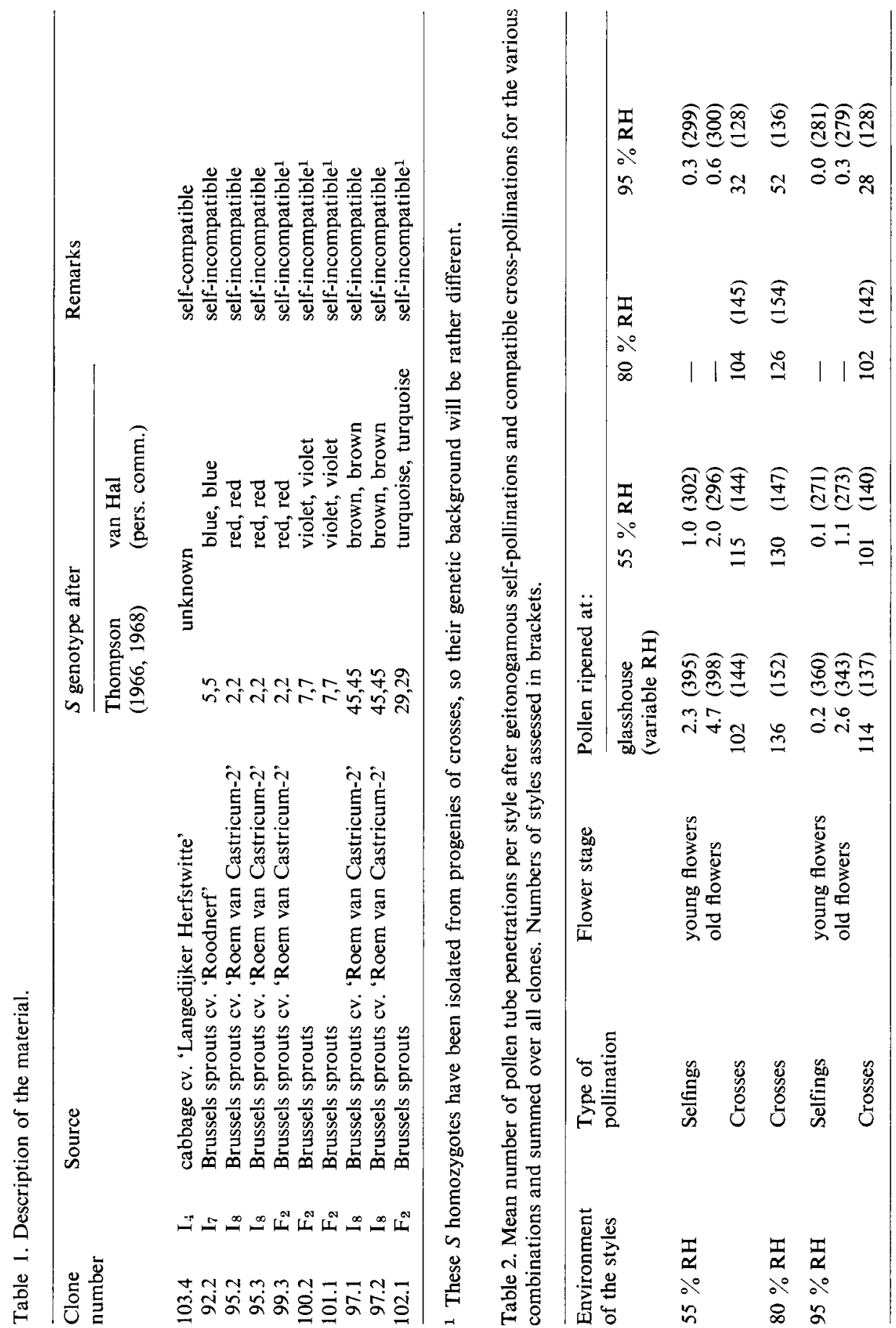


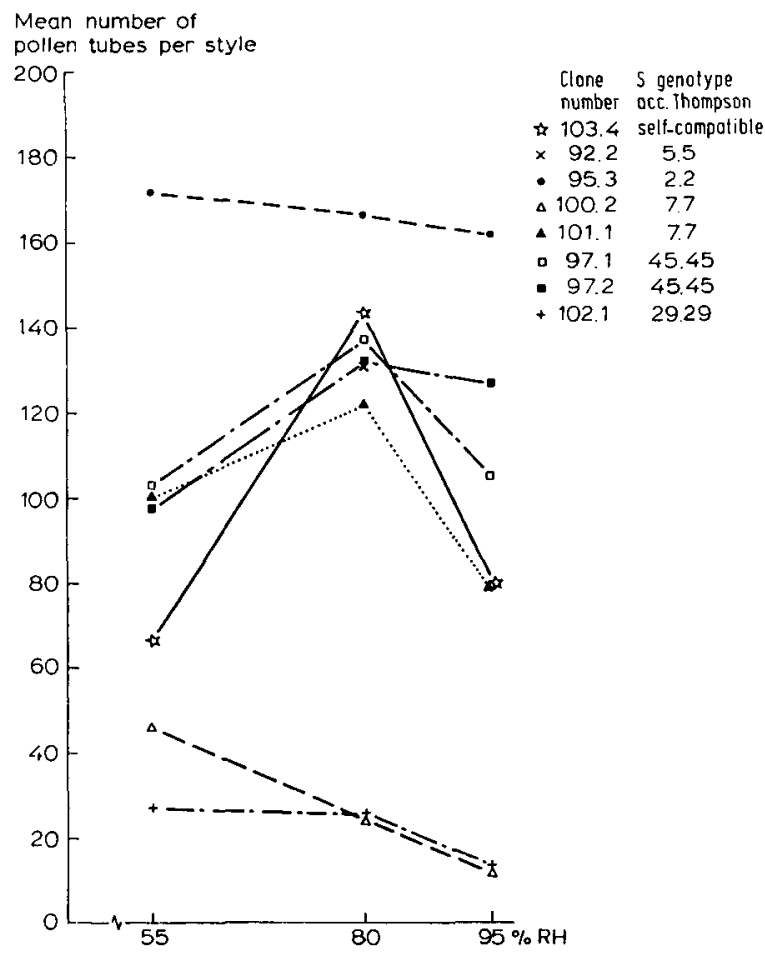

Fig. 2. Mean pollen tube penetration into the styles after compatible crossing (mean values over all pollen environments).

flowers were selfed practically no penetration of pollen tubes into the styles was observed, no matter what the origin of the pollen was.

The graphs for the compatible crosses (Fig. 2) showed a slight optimum for pollen tube penetration at $80 \% \mathrm{RH}$ for most clones, but the graphs of three clones showed a slightly decreased pollen tube penetration with increasing humidity of the style environments. A wide variation between the compatibility levels of the clones could also be observed.

A definite conclusion regarding the effect of $\mathrm{RH}$ on the style cannot be drawn from this experiment, because the styles remained in their respective environments after pollination. The effect of RH on styles is therefore confounded with a possible influence of RH on pollen germination and pollen tube penetration after pollination.

\section{Effect of $R H$ on pollen}

Fig. 3 shows the effect of RH on the pollen for incompatible selfings. In the old flower stage (Fig. 3B) a decrease in pollen tube penetration can be observed at high RH. The self-compatible clone 103.4 showed a very clear decrease with higher humidity. In the young flower stage (Fig. 3A) the self-incompatible clones showed hardly any change in pseudocompatibility after selfing with pollen from the two 
humidity environments. Differences between the self-incompatible clones were very small or absent. Lawson (1974) was also not able to demonstrate such differences between self-incompatible clones or $S$ genotypes.

The effect of RH on pollen tube penetration was the same for young and old flowers (Fig. 3A and 3B). In this experiment the normal increase of pseudocompatibility with flower age was also observed after selfing.

For the compatible crosses (Fig. 4) mostly a slight decrease of pollen tube penetration could be observed from 55 to $80 \% \mathrm{RH}$, but from 80 to $95 \% \mathrm{RH}$ there was a clear decrease. Pollen ripened in the glasshouse at a RH of about $75 \%$ (65 to $80 \%$ ) gave nearly the same degree of pollen tube penetration as pollen from 55 or $80 \% \mathrm{RH}$. So high humidity had a negative effect on the pollen ripened under these conditions. In general the effect of RH on pollen tube penetration has been the same for most clones and $S$ genotypes. Differences between the clones could be observed. Clones 100.2 and 102.1 showed a very low level of pollen tube penetration after crossing. Therefore the results of the selfings of clone 100.2, as shown in Fig. 3, should be considered with suspicion.

The decreased pollen tube penetration might be caused by deterioration of pollen ripened at very high humidity. Maybe pollen grains germinate under high RH conditions as soon as the anthers dehisce. This would agree with the increase of pollen germination and tube growth after incompatible pollination under high humidity conditions as described by Oelke (1957), Christ (1959) and Tatebe (1964). If this
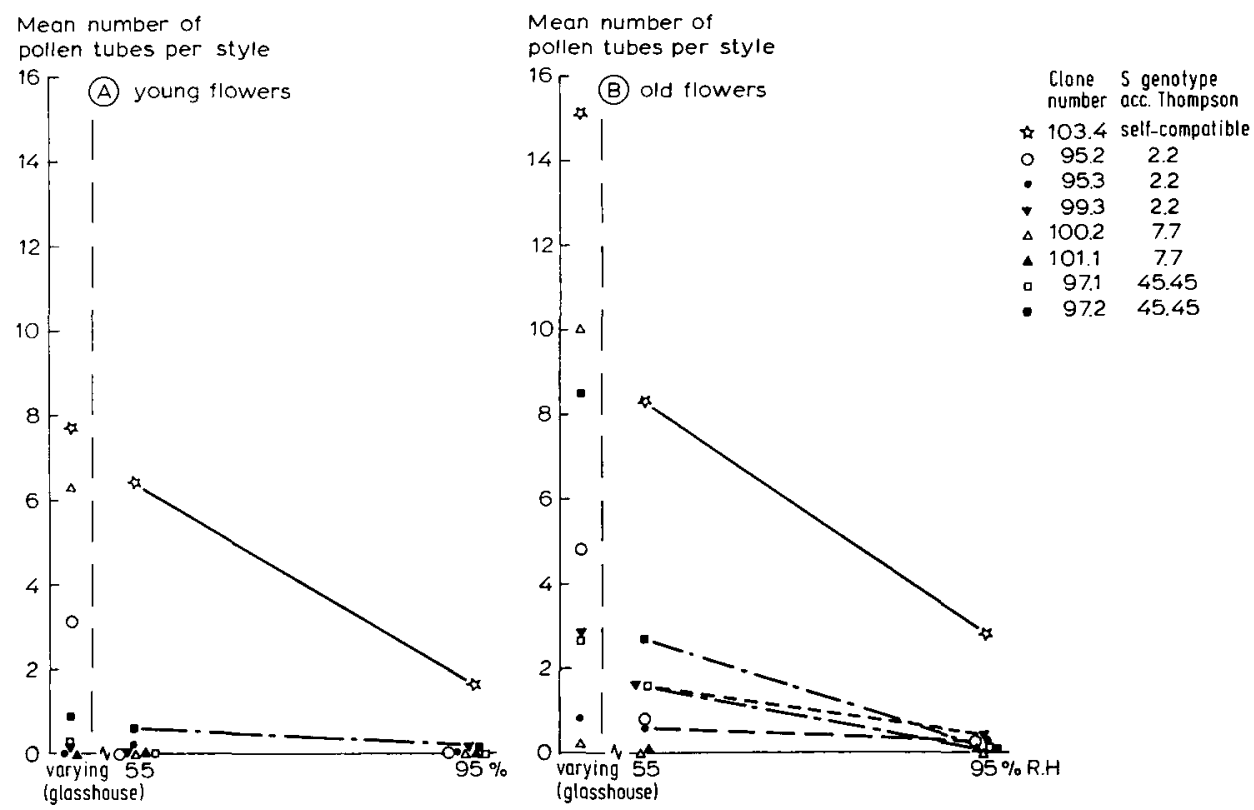

Fig. 3. Effect of relative humidity on pollen after selfing of young and old flowers (mean values over all style environments). 


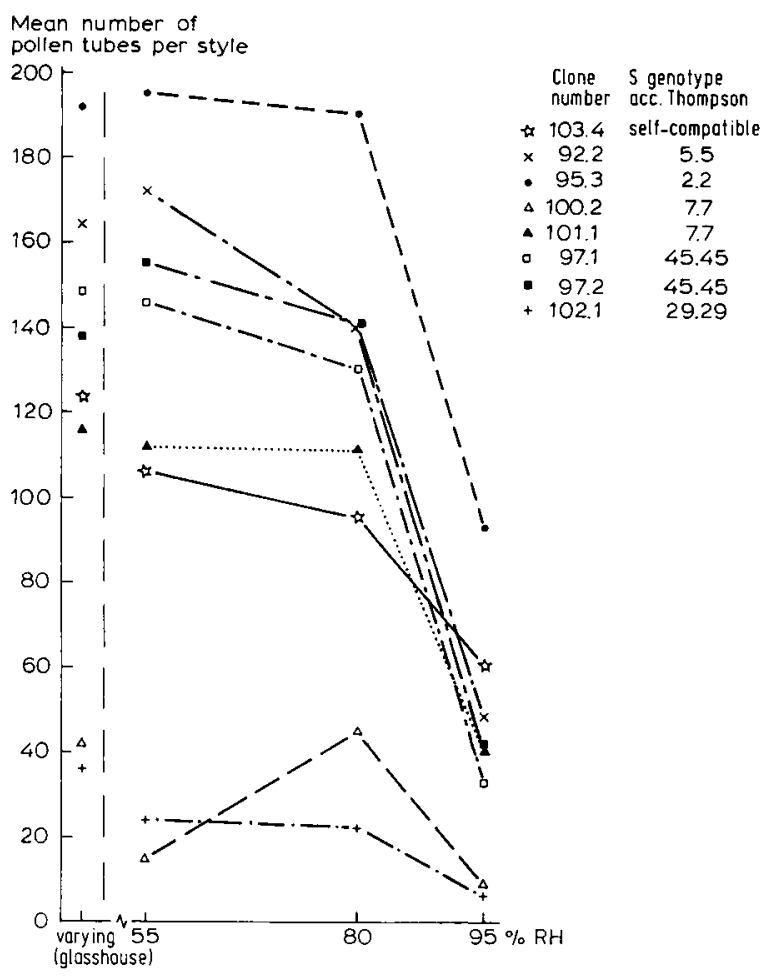

Fig. 4. Effect of relative humidity on pollen after compatible crossing (mean values over all style environments).

were true a smaller quantity of viable pollen would have been available than after pollinations with pollen from the other environments resulting in a lower amount of pollen tube penetration. To prove this more research will be necessary.

\section{Conclusions}

Self incompatibility is hardly influenced by RH. Though pollen germination and tube growth are promoted by high RH, pollen tube penetration into the styles decreases rather much. This results from a decrease in fertility of pollen ripened at high RH.

\section{References}

Carter, A. L. \& T. McNeilly, 1975. Effect of increased humidity on pollentube growth and seed set following self pollination in Brussels sprout (Brassica oleracea var. gemmifera). Euphytica 24: 805-813.

Christ, B., 1959. Entwicklungsgeschichtliche und Physiologische Untersuchungen über die Selbststerilität von Cardamine pratensis L. Z. Bot. 47: 88-112. 
Kho, Y. O. \& J. Baër, 1968. Observing pollen tubes by means of fluorescence. Euphytica 17: 298-302.

Kroh, M. \& H. F. Linskens, 1963. Biochemie der Befruchtungs-'Inkompatibilität'. Die Ursache für die Unfruchtbarkeit von Blütenpflanzen bei Selbstbestaubung. I. Umschau 63: 266-269.

Lawson, J., 1974. The causes of pseudocompatibility in Brassica oleracea L. Ph. D. Thesis, Univ. Newcastle upon Tyne, $122 \mathrm{pp}$.

Linskens, H. F. \& M. Kroh, 1967. Inkompatibilität der Phanerogamen. Handbuch der PflanzenPhysiologie, Bd. 18: 506-530.

Marrewijk, N. P. A. van \& D. L. Visser, 1974. The influence of alternating temperatures and relative humidity on the activity of $S$-alleles in Brassica oleracea L. var. gemmifera. (DC.) Schulz. In: Cruciferae 1974, Proc. Eucarpia Meeting-Cruciferae 1974, S.H.R.I., Dundee: 20-26.

Oelke, J., 1957. Zur Physiologie der Selbst- und Kreuzungssterilität beim Radieschen (Raphanus sativus). Züchter 27: 358-369.

Tatebe, T., 1964. Studies on the physiological mechanism of self-incompatibility in Japanese radish, I. Influence of air humidity on self fertility. J. Jap. Soc. hort. Sci. 33: 62-66.

Thompson, K. F., 1968. Classified $S$-alleles for Brassica-breeders. Proc. Brassica Meeting of Eucarpia, September 1968. NVRS, Wellesbourne: 25-28.

Thompson, K. F. \& J. P. Taylor, 1966. Non-linear relationships between $S$-alleles. Heridity (London) 21: 345-362.

Smeets, L., 1978. The phytotron of the Institute for Horticultural Plant Breeding (IVT) at Wageningen, the Netherlands. A revision of previous descriptions, Neth. J. agric. Sci. 26: 8-12. 